\title{
A comparison of the therapeutic effectiveness of gastrin neutralisation in two human gastric cancer models: relation to endocrine and autocrine/paracrine gastrin mediated growth
}

\author{
S A Watson, T M Morris, A Varro, D Michaeli, A M Smith
}

\begin{abstract}
Background-Gastrin is a growth factor for established tumours.

Aims-To investigate the therapeutic effect of antibodies, raised against the Gastrimmune immunogen, which neutralise the glycine extended and carboxy amidated forms of gastrin 17 in two human gastric cancer models.

Methods-MGLVA1 cells (which have a gastrin autocrine/paracrine phenotype) and ST16 cells (which have an endocrine phenotype) were injected into the peritoneal cavity of SCID mice. Peritoneal tumours, ascites, and cachexia formation occurred, with the monitored endpoint being morbidity.

Results-In MGLVA1 cells, intravenous administration of antibodies raised against Gastrimmune increased the $50 \%$ median survived by $25 \%$ at three different initial cell seeding concentrations $(1 \times$ $10^{6}-5 \times 10^{5}$ per mouse). In ST16 cells, the effect of Gastrimmune induced antibodies on time to morbidity was greatest at the lowest cell seeding concentration $\left(5 \times 10^{5}\right.$ cells/mouse) with the $50 \%$ median survival increased by $74 \%$ and overall survival achieved in $38 \%$ of the mice.

Conclusions-Gastrimmune may have potential therapeutic benefit on gastrin sensitive gastric tumours and may interact with both endocrine and autocrine mediated growth pathways.

(Gut 1999;45:812-817)
\end{abstract}

Keywords: gastrin; gastric cancer; Gastrimmune; autocrine/paracrine growth

Gastrin has been shown to be a growth factor for gastric tumours in both established cell lines $^{1-3}$ as well as cells derived from human gastric tumour specimens. ${ }^{34}$ In the latter studies, malignant cells were shown to have heightened sensitivity to the proliferative effects of gastrin when compared with corresponding normal gastric epithelial cells.

Few studies have examined cholecystokinin $\mathrm{B} /$ gastrin receptor (CCKBR) expression on gastric cancers. Matsushima and colleagues ${ }^{5}$ showed there was no expression of the mRNA for the CCKBR in a series of gastric adenocarcinoma cell lines or surgically resected human gastric adenocarcinomas. However, examination of the mRNA expression for CCKBR is potentially problematic due to the presence of splice variants ${ }^{6}$ and use of novel exons such as exon $1 b{ }^{7}$ the latter generating a truncated isoform. Using primers and probes designed to detect both total CCKBR expression (by using conserved sequences) and truncated CCKBR expression (specific to exon 1b), mRNA expression of the respective receptor isoforms were shown in $4 / 5$ and $3 / 5$ gastric adenocarcinoma cell lines, respectively. ${ }^{8}$ In addition, western blotting studies performed using antiserum directed against the human CCKBR also detected expression of the receptor on human gastric tumour cell lines. ${ }^{9}$

The presence of a potential gastrin autocrine/paracrine pathway has been reported to exist in gastric cancer cell lines. ${ }^{10}{ }^{11}$ In both studies, gastric cancer cell lines were shown to secrete precursor gastrin peptides, and a number of studies have now shown that precursor gastrin species may have proliferative action on both normal gastrointestinal (GI) epithelium ${ }^{12}$ as well as GI tumours, ${ }^{13-15}$ including gastric tumours. ${ }^{16}$

The aim of the present study was to evaluate the effect of the gastrin immunogen, Gastrimmune on two human gastric cancer cell lines with differing profiles of cell associated gastrin peptides. Gastrimmune is composed of the amino terminus of human gastrin 17 (G17) linked to diphtheria toxoid which, when administered in situ, raises antibodies which cross react with amidated G17 and the precursor gastrin form, glycine extended G17, but not the related hormone, CCK. ${ }^{17}$

Materials and methods

CELL LINES

MGLVA1 is an ascitic variant of the human gastric cell line, MKN45G. ${ }^{18} \mathrm{ST} 16$ is a human gastric cell line originally derived in the Cancer Research Campaign Labs, University of Nottingham, UK from a patient specimen. In vitro, the cell lines were maintained in RPMI 1640 medium (Gibco, Irvine, Scotland) supplemented with $10 \%$ heat inactivated foetal calf serum (FCS, Sigma, Poole, Dorset) and grown at $37^{\circ} \mathrm{C}$ in $5 \% \mathrm{CO}_{2}$ and humidified conditions.

Abbreviations used in this paper: $\mathrm{ABC}$, antigen binding capacity; CCK, cholecystokinin; CCKBR, $\mathrm{CCKB} /$ gastrin receptors; DEPC, diethyl pyrocarbonate; G17, gastrin 17; GI, gastrointestinal; GlyG17, glycine extended gastrin 17; SCID, severe combined immunodeficient. 
REVERSE TRANSCRIPTASE POLYMERASE CHAIN REACTION (RT-PCR) FOR DETECTION OF GASTRIN mRNA

Total RNA was extracted from cell lines using RNAzol-B (Biogenesis, Poole, Dorset) according to the manufacturer's instructions. Cells were lysed in $1 \mathrm{ml}$ RNAzol-B with $110 \mathrm{ml}$ chloroform (Sigma). An aqueous phase was separated by a $1300 \mathrm{~g}$ spin at $4^{\circ} \mathrm{C}$ for $30 \mathrm{~min}-$ utes and eluted. RNA from the eluate was precipitated in ice cold isopropanol and washed twice in $75 \%$ ethanol. The RNA pellet was then resuspended in $50 \mu \mathrm{l}$ sterile diethyl pyrocarbonate (DEPC) treated water.

Reverse transcription was performed as described previously. ${ }^{19}$ Total RNA preparations were divided into two halves and incubated at $70^{\circ} \mathrm{C}$ for 10 minutes with random hexamer primers $\left(\mathrm{pd}(\mathrm{N})_{6}\right.$; GibcoBRL) and then cooled immediately on ice. One half was converted into cDNA while the other half acted as a control and was incubated in a reaction mix without the reverse transcriptase enzyme. Reaction mixes consisted of a $50 \mu \mathrm{l}$ volume containing $30 \mu \mathrm{mol}$ dNTPs (Pharmacia, St Albans, Herts), 0.01 M DTT (GibcoBRL), and 200 units Superscript reverse transcriptase which was buffered in 1st Strand Buffer (GibcoBRL). Reactions were carried out at $25^{\circ} \mathrm{C}$ for $10 \mathrm{~min}$ utes and $37^{\circ} \mathrm{C}$ for one hour with a denaturing stage of $95^{\circ} \mathrm{C}$ for five minutes.

A gastrin PCR reaction ( $50 \mu \mathrm{l}$ volume) was performed using 2.5 units of Taq polymerase (Qiagen, UK), $40 \mu \mathrm{mol}$ dNTPs (Pharmacia), and $10 \mu \mathrm{mol}$ of each primer in $1 \times$ PCR buffer (Qiagen). Samples were separated on $1.5 \%$ (wt/vol) agarose gels and subjected to Southern blotting. The blots were hybridised at $52^{\circ} \mathrm{C}$ with digoxygenin (DIG) labelled oligonucleotide probes and washed at $47^{\circ} \mathrm{C}$ in $2 \times$ saline sodium citrate (SSC) $/ 1 \%$ sodium dodecyl sulphate (SDS), and $0.5 \times$ SSC, both twice for five minutes. Any signal was detected using antiDIG-AP antibodies and the CDP-Star chemiluminescent substrate (Boehringer Mannheim), both used according to the manufacturer's instructions. A 15 minute exposure to an $x$ ray film was used to detect the chemiluminescence.

ENZYME LINKED OLIGONUCLEOTIDE LINKED CHEMILUMINESCENT ASSAY (ELOCA)

RNA extraction and reverse transcription were both performed as above. PCR was performed using a similar protocol to that described previously $^{19}$ using $1 \mu \mathrm{l}$ of cDNA. Reactions were prepared in a $50 \mu$ volume containing 1.0 unit Dynazyme (Flowgen) in $1 \times$ PCR buffer (Flowgen) with $40 \mu \mathrm{mol}$ dNTPs (Pharmacia) and $10 \mu \mathrm{mol}$ of each primer. One drop of mineral oil was layered on top of the reaction mix which was incubated at $94^{\circ} \mathrm{C}$ for four minutes before cycles of $94^{\circ} \mathrm{C}$ for 60 seconds, $54^{\circ} \mathrm{C}$ for 90 seconds, and $72^{\circ} \mathrm{C}$ for 60 seconds. These cycles were repeated 23 times for GAPDH and 30 times for gastrin. A final incubation of $72^{\circ} \mathrm{C}$ for 600 seconds was performed immediately afterwards to convert all PCR products to double stranded DNA. The PCR reactions were dot blotted in duplicate onto Hybond- $\mathrm{N}^{+}$ membrane (Amersham International) according to the ELOCA method. ${ }^{19}$ It was found that $1 \mu \mathrm{l}$ of GAPDH and $10 \mu \mathrm{l}$ of gastrin PCR reactions were optimal for semiquantitative detection. Calibration curves, containing known quantities of purified PCR product for glyceraldehyde-3-phosphate dehydrogenase $(\mathrm{GAPDH})$ and gastrin were also blotted. The blots were hybridised at $37^{\circ} \mathrm{C}$ using $2 \times$ SSC $/ 1 \%$ SDS and $0.5 \times$ SSC, twice each for five minutes. Blots were then incubated with anti-DIG-AP and CDP-Star as described above. After incubation with the chemiluminescent substrate, semiquantitation was performed by placing the blots in a Top Count (Hewlett Packard) and counting the chemiluminescence associated with each dot. The calibration curve was plotted on a log-log graph from which sample values were determined. A gastrin/GAPDH ratio was calculated in order to standardise for sample size.

RADIOIMMUNOASSAY OF CELL ASSOCIATED AND SECRETED GASTRIN LEVELS

Cells were seeded into T75 (Costar) flasks containing serum free medium composed of RPMI 1640 medium in a 1:1 ratio with HAMS F12 (Gibco) containing 0.5\% bovine serum albumin (BSA, Sigma). When the cell monolayers had reached confluence, they were harvested, pelleted in $1 \mathrm{ml}$ of sterile phosphate buffered saline, pH 7.2 (PBS, Oxoid, Bucks), and heated in a boiling water bath. Spent media from the cell lines were centrifuged to remove cell debris and dialysed overnight in PBS. The levels of progastrin, glycine extended gastrin, and carboxy amidated gastrin were measured by radioimmunoassay (RIA) using the specific antisera L289, 109-21, and L2, respectively which have been described previously. ${ }^{20}$

IN VITRO ASSESSMENT OF CELL GROWTH RATES AND EFFECT OF TREATMENT WITH ANTISERUM RAISED AGAINST GASTRIMMUNE

Cells were seeded into 96 flat bottomed well plates (Costar) at a concentration of $1 \times 10^{4}$ per well in a $100 \mu \mathrm{l}$ volume in the serum free medium. After 72 hours, cell proliferation was assessed by the methylthiazoyl tetrazolium (MTT) assay. ${ }^{21}$

Protein A purified immunoglobulins (IgG) raised against Gastrimmune (test serum) and normal rabbit control IgG were normalised to a standard protein concentration of $0.5 \mathrm{mg} / \mathrm{ml}$. Cells were seeded into the 96 well plates described above at a concentration of $1 \times 10^{4}$ per well in a $100 \mu \mathrm{l}$ volume in serum free medium. IgG dilutions from $1 / 20$ to $1 / 1000$ were prepared in serum free medium (relating to antigen binding capacities (ABCs) ranging from $5.5 \times 10^{-8}$ to $1.1 \times 10^{-9} \mathrm{M}$ for amidated G17 (affinity $0.15 \mathrm{nM}$ ) and $2 \times 10^{-7}$ to $4 \times 10^{-9}$ $\mathrm{M}$ for GlyG17 (affinity $0.47 \mathrm{nM}$ )) and added to the cells in $100 \mu \mathrm{l}$ volumes per well. Each condition was performed with five replicates. Cell proliferation was assessed after 72 hours by the MTT assay. 


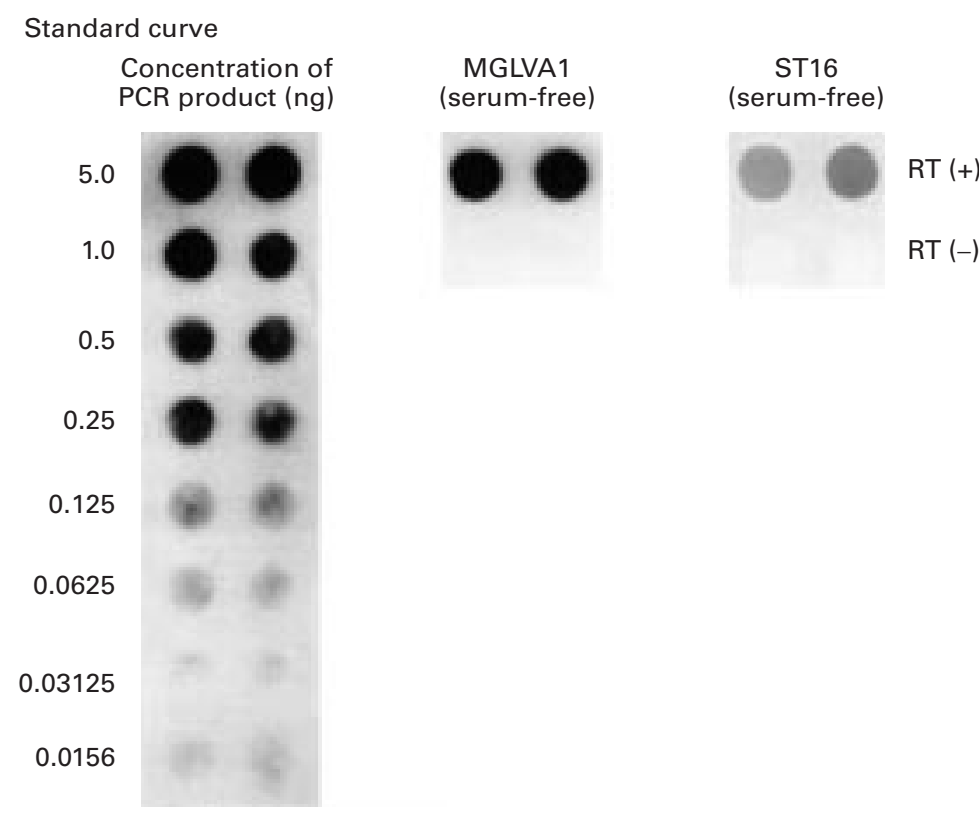

Figure 1 A Southern blot showing gastrin mRNA expression of MGLVA1 and ST16 cells grown in serum free conditions in vitro. The standard curve is generated with PCR products from a gastrin positive control (human $G$ cells) of known DNA content.

INITIATION OF IN VIVO ASCITES MODELS

Severe combined immunodeficient (SCID) mice, aged 6-10 weeks (Cancer Studies Unit, University of Nottingham) were used for the in vivo studies. The mice were fed and watered ad libitum.

Cells were harvested from semiconfluent monolayers and suspended at the required concentration in sterile PBS. A $1 \mathrm{ml}$ volume was then injected into the peritoneal cavity of the experimental mice, randomised such that animal weights were equalised across the experimental groups, which were composed of 8-16 animals of mixed sex.

Animals were inspected daily and, at the onset of morbidity (cachexia, weight loss, and abdominal swelling due to ascites formation), termination was carried out by an experienced independent observer who was blind to the treatment groups. Initial validation studies showed that variation in solid tumour burden (diffusely spread throughout the peritoneal cavity), ascites volume, and cell density between animals, at onset of morbidity, were within $15 \%$. Thus the model allows the assessment of time taken to achieve a definitive tumour burden.
IN VIVO ADMINISTRATION OF ANTIBODIES RAISED BY GASTRIMMUNE

Antisera were raised in rabbits by immunisation with Gastrimmune as described previously $^{22}$ and denoted rabbit anti-G17 (9):DT. Normal rabbit antiserum was used as the vehicle control. Antiserum was administered from day 1 following tumour cell injection, intravenously, once daily, at a concentration generating a stable serum $\mathrm{ABC}$ of $7.5 \times 10^{-9} \mathrm{M}$ for amidated $\mathrm{G} 17$ and $3 \times 10^{-8} \mathrm{M}$ for GlyG17. ${ }^{17}$

All animal experimentation was performed according to the UK Coordinating Committee for Cancer Research (UKCCCR) guidelines.

STATISTICS

Statistical evaluation of in vitro data was performed by a one way analysis of variance, and survival analysis was assessed using a log rank test, both on the SPSS statistical package.

\section{Results}

mRNA LEVELS IN MGLVA1 AND ST16 AS

DETERMINED BY THE ELOCA ASSAY

The gastrin/GAPDH mRNA levels were determined for MGLVA1 and ST16 cells growing in vitro in both serum containing and serum free media. In serum free medium the gastrin: GAPDH ratio was 0.0909 for MGLVA1 and 0.0052 for ST16 cells, showing a 17.5 fold increase with MGLVA1 cells. When the cells were grown in serum containing medium, the ratio was reduced by $76 \%$ to 0.0217 in MGLVA1 cells and to 0.0015 in ST16 cells (71\% reduction). This experiment has been repeated twice with similar results (fig 1 shows a representative Southern blot).

Both cell lines have previously been shown to express mRNA for the truncated and classical $\mathrm{CCKBR}^{8}$ as well as the receptor protein as characterised by western blotting. ${ }^{9}$

\section{CELL ASSOCIATED AND SECRETED GASTRIN}

LEVELS AS DETERMINED BY RADIOIMMUNOASSAY

Table 1 presents the results. MGLVA1 has previously been shown to secrete cell associated progastrin and glycine extended gastrin but not carboxy amidated gastrin. ${ }^{23}$ ST16 had cell associated progastrin but no cell associated glycine extended or carboxy amidated gastrin, and no detectable secreted gastrin species. Growth of both of the cell lines in serum containing growth medium, resulted in a lack of detection of gastrin peptides by the RIA.

Table 1 Cell associated and secreted gastrin species in human gastric tumour cell lines

\begin{tabular}{|c|c|c|c|c|}
\hline \multirow[b]{3}{*}{ Cell line } & \multicolumn{4}{|c|}{ Mean gastrin levels $\left(\mathrm{fmol} / 5 \times 10^{6} \mathrm{cells}\right)$} \\
\hline & \multicolumn{2}{|l|}{ Cell associated } & \multirow{2}{*}{$\frac{\text { Secreted }}{\text { Progastrin }}$} & \multirow[b]{2}{*}{ Glygastrin } \\
\hline & Progastrin & Glygastrin & & \\
\hline MGLVA1* & $607.0(53.0)$ & $212.0(40.3)$ & $39.7(34.0)$ & $68.7(18.6)$ \\
\hline ST16 & $182.3(54.8)$ & ND & ND & ND \\
\hline
\end{tabular}

Results expressed as mean (SD) ( $\mathrm{n}=2$ separate experiments).

${ }^{\star}$ From Watson et al. ${ }^{23}$

Carboxy amidated gastrin was not detected in any cell extract examined.

ND, not detected. 

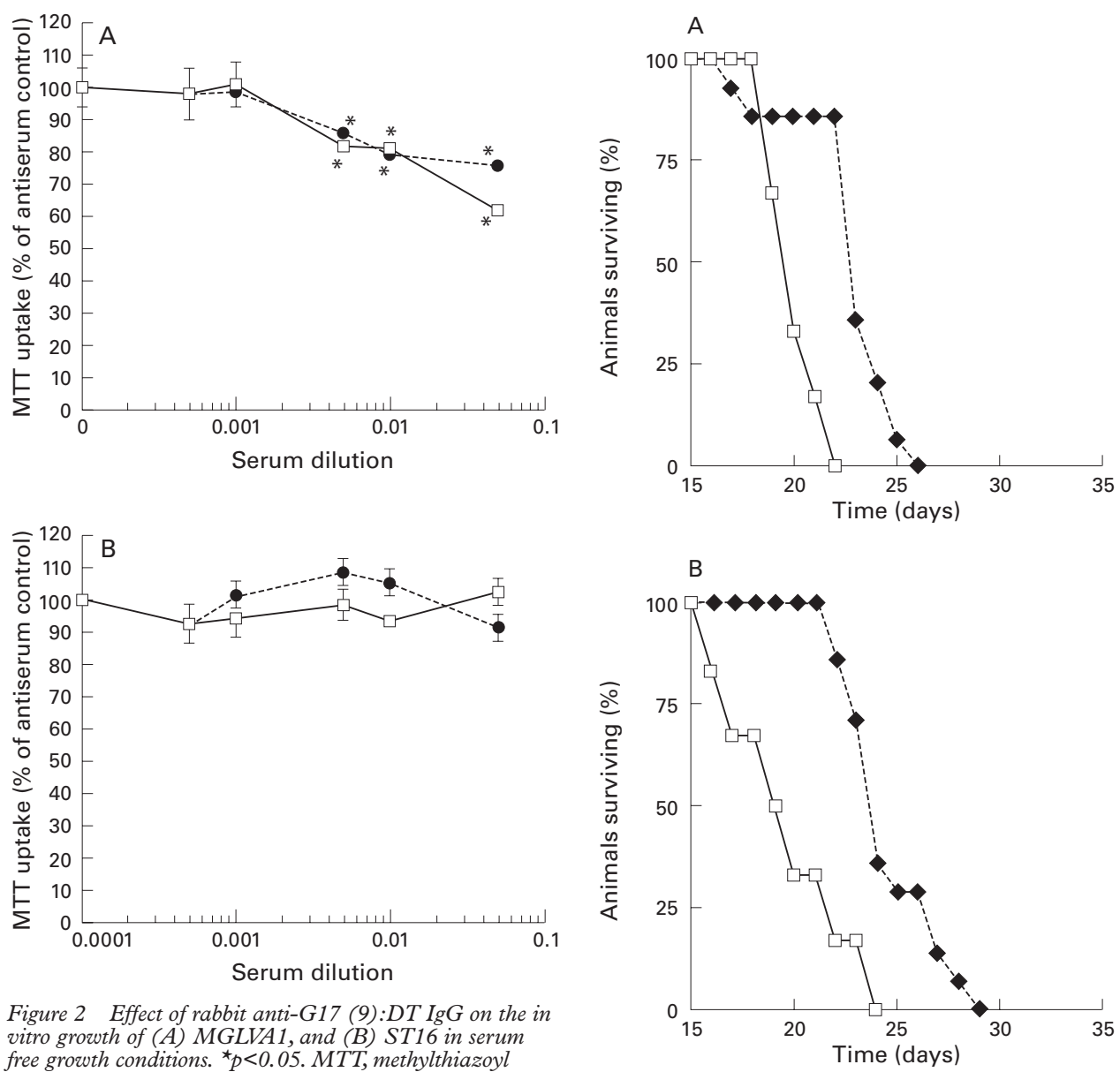

Figure 2 Effect of rabbit anti-G17 (9):DT IgG on the in
vitro growth of $(A) M G L V A 1$, and (B) ST16 in serum free growth conditions. ${ }^{\star} p<0.05$. MTT, methylthiazoyl tetrazolium.

IN VITRO GROWTH LEVELS IN SERUM FREE MEDIUM

MTT uptake was used to measure in vitro proliferation which assesses the oxidative ability of the cell to convert a soluble tetrazolium compound into an insoluble coloured crystalline product which can be dissolved and assessed colorimetrically. This has previously been shown to correlate with direct cell counts of human G1 cell lines. ${ }^{21}$ The mean basal MTT uptake of ST16 from three experiments was 0.513 with a standard deviation of 0.08 compared with a mean of 0.906 for MGLVA1 with a standard deviation of 0.03 ( $p<0.001$, Student's $t$ test). ST16 has previously been shown to respond proliferatively to exogenously administered G17 in vitro, ${ }^{24}$ whereas MGLVA1 showed no proliferative response. ${ }^{18}$ Figure 2 shows the MTT uptake of MGLVA1 and ST16 in the presence of increasing dilutions of rabbit anti-G17 (9):DT (calculated as a percentage of normal rabbit IgG control at each antiserum dilution). In two experiments, the growth of MGLVA1 was significantly reduced by treatment with rabbit anti-G17 (1-9):DT IgG to $30-40 \%$ of control at a $1 / 20$ dilution, relating to an $\mathrm{ABC}$ of $5 \times 10^{-7} \mathrm{M}$ (fig 2A), and modestly inhibited at dilutions of $1 / 100$ and $1 / 200$ ( $p<0.05$, one way analysis of variance). The growth of ST16 was not significantly reduced in the two experiments performed (fig 2B).

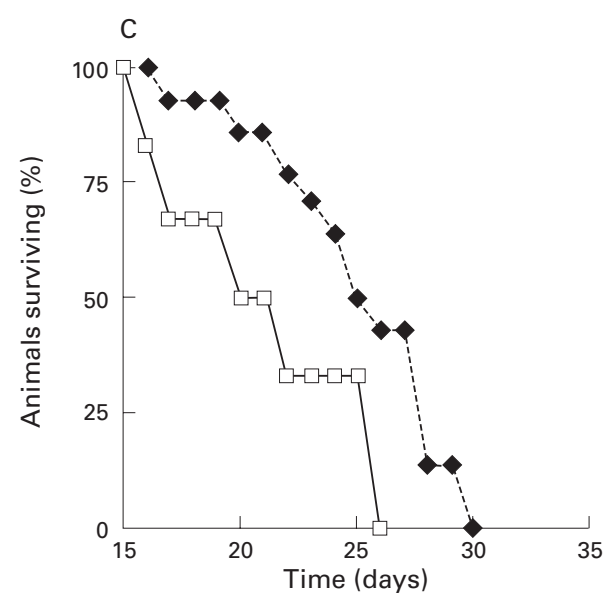

Figure 3 Effect of Gastrimmune induced antiserum on the in vivo growth of MGLVA1 cells at three different seeding concentrations: $(A) 1 \times 10^{6}$; (B) $7.5 \times 10^{5}$; (C) $5 \times$ $10^{5}$.

IN VIVO EFFECT OF ANTISERUM RAISED AGAINST GASTRIMMUNE

Figure 3 shows the effect of rabbit anti-G17 (9):DT treatment on mice injected with increasing concentrations $\left(5 \times 10^{5}\right.$ to $1 \times 10^{6}$ cells per mouse) of MGLVA1 cells. With initial cell concentrations of $1 \times 10^{6}$ there was a significant effect on survival by treatment with rabbit anti-G17 (9):DT when compared with normal rabbit ( $\mathrm{p}=0.0124, \log$ rank test) with $50 \%$ median survival increasing by $21 \%$ from 19 days to 23 days (fig 3A). A significant effect 

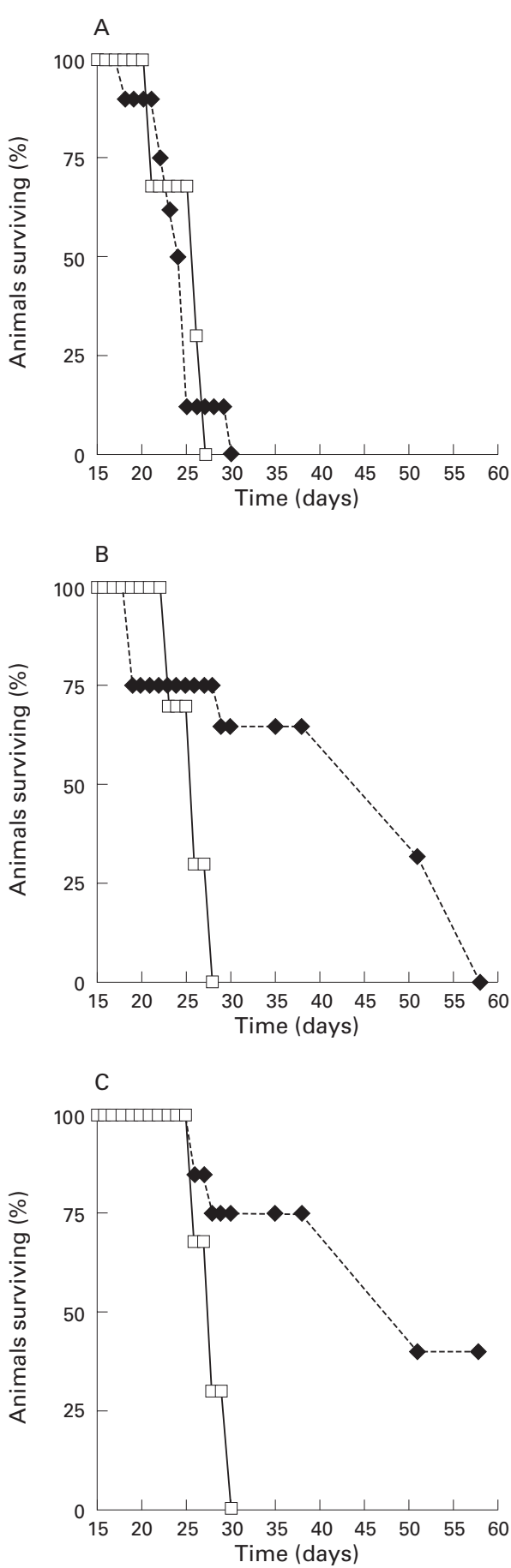

Figure 4 Effect of Gastrimmune induced antiserum on the in vivo growth of ST16 cells at three different seeding concentrations: $(A) 1 \times 10^{6}$; (B) $7.5 \times 10^{5}$; (C) $5 \times 10^{5}$.

on survival, following treatment with rabbit anti-G17 (9):DT, was also seen when the cell concentration was reduced to $7.5 \times 10^{5}$ cells $(p=0.0023$ when compared with normal rabbit control) with the $50 \%$ median survival increasing by $26.3 \%$ from 19 days to 24 days (fig 3B). When the seeding concentration was lowered to $5 \times 10^{5}$ cells/mouse, treatment with rabbit anti-G17 (9):DT increased the 50\% median survival by $25 \%$ from 20 days to 25 days $(\mathrm{p}=0.0146$, fig 3C).

Figure 4 shows the effect of rabbit anti-G17 (9):DT treatment on mice injected with increasing concentrations of ST16 cells. With initial cell innocula of $1 \times 10^{6}$ cells, no significant effect on survival was achieved (fig $4 \mathrm{~A})$. When mice were injected with cell concentrations of $7.5 \times 10^{5}$ cells, the $50 \%$ median survival was increased by $72 \%$ from 25 to 43 days in the rabbit anti-G17 (9):DT treated group $(\mathrm{p}<0.0001$, fig $4 \mathrm{~B})$. When mice were injected with $5 \times 10^{5}$ cells, the median $50 \%$ survival was 27 days following normal rabbit IgG treatment and 47 days following treatment with rabbit anti-G17 (9):DT (fig 4C, $\mathrm{p}<0.0001,74 \%$ increase). Tumour burden, ascites volume, and density were consistent in all animals at onset of morbidity. However, at day 60, there was no evidence of tumour within the peritoneal cavity of rabbit anti-G17 (9):DT antiserum treated mice.

\section{Discussion}

Treatment with antibodies raised by Gastrimmune have previously been shown to inhibit growth of the human colorectal xenograft, $\mathrm{AP} 5^{22}$ and the syngeneic rat colon tumour, DHDK12. ${ }^{17}$ In these models, both cell lines were responsive to exogenously administered gastrin as well as expressing the peptide in an endogenous manner and when grown in vivo, antibodies raised against Gastrimmune exerted approximately $50 \%$ inhibition of tumour growth. Although representative of the situation likely to exist in the human scenario, the contribution Gastrimmune antibodies make to inhibiting each individual pathway is not known. This was therefore addressed in the present study by administration of Gastrimmune antibodies to two human gastric cell lines, MGLVA1 and ST16, the former associated with an autocrine and the latter with an endocrine gastrin mediated growth pathway.

The effect of Gastrimmune antibodies on normal physiology has been evaluated in the rat and pig. ${ }^{25}{ }^{26}$ Antibodies raised by Gastrimmune had no effect on basal acid secretion but reduced acid secretion induced by infusion of G17. ${ }^{25}$ Histological analysis of the pig gastric mucosa following active immunisation with Gastrimmune showed no antitrophic effect on the gastric mucosa. ${ }^{26}$

The MGLVA1 cell line is not responsive to exogenously administered gastrin in vitro, ${ }^{18}$ but in the present study expressed gastrin mRNA; it has previously been shown to express cell associated and secreted glyG17. ${ }^{23}$ Gastrin mRNA levels were shown to be elevated in serum restricted conditions in vitro and the cell line was shown to proliferate in such conditions. MGLVA1 may therefore exhibit an autocrine gastrin phenotype, as glyG17 has previously been shown to exert a proliferative effect on tumour cell growth. ${ }^{13-16}$ Amidated gastrin was not detectable by the RIA used. Previous immunocytochemical studies have shown amidated gastrin within a small percentage of MGLVA1 cells ${ }^{9}$ and thus secreted and cell associated levels may be below the detection limit of the RIA assay. If glyG17, secreted by MGLVA1, is acting in an autocrine manner, antibodies raised by Gastrimmune may interrupt the autonomous growth loop. In vitro, 
antibodies raised against Gastrimmune neutralised the basal growth of MGLVA1, suggesting that this was so. This was also shown in vivo with a reproducible increase in time to morbidity following administration of Gastrimmune induced antibodies, which did not seem to be dependent on cell seeding concentration. At termination the tumour burden was consistent between animals, signifying that Gastrimmune exerted a cytostatic effect in this model with a delay in time taken to reach a critical tumour burden.

From the in vitro gastrin secretion studies, it can be calculated that glyG17 secreted by MGLVA1 in vivo may achieve local tumour concentrations in the fM level. As the affinity of Gastrimmune induced antibodies for glyG17 is $0.47 \mathrm{nM}$, the therapeutic effects observed could potentially be enhanced by increasing the affinity of the antibodies for glycine extended gastrin.

ST16 appears to have a different gastrin growth profile to MGLVA1 in that it has previously been shown to respond to exogenous amidated G17 in vitro, ${ }^{24}$ but does not secrete glyG17 or amidated G17 and consequently is not inhibited by antibodies raised against Gastrimmune in vitro. The cell line expresses $\mathrm{CCKB} /$ gastrin receptors ${ }^{8}$ and thus when grown in vivo, may potentially respond to serum associated amidated G17 in an endocrine manner. Administration of Gastrimmune induced antibodies exerted strong therapeutic effects on the in vivo growth of ST16 with complete survival achieved in $38 \%$ of mice, at the lowest cell seeding concentration. At a low cell seeding the cytostatic effects on cell growth induced by Gastrimmune antibodies may prevent tumour establishment.

With ST16 the scenario is potentially different to that with MGLVA1 in that antibodies raised by Gastrimmune could potentially neutralise the proliferative gastrin species, amidated G17, at a site distant from the tumourthat is, within the serum. The affinity of antibodies raised by Gastrimmune is adequate to neutralise serum amidated G17 levels, which are in the $0.5 \mathrm{nM}$ range.

Gastrimmune is currently in Phase III trials in stage II and III gastric cancer. Patients are being immunised after operation at confirmation of histological stage, and the effect on survival is being assessed. Thus, it is important to determine whether Gastrimmune antibodies can reduce the growth of peritoneal seeding of tumour. The ability of Gastrimmune antibodies to delay the growth of two gastric tumour cell lines seeded at a relatively high level into the peritoneal cavity has been confirmed in the present study.

In conclusion, Gastrimmune immunisation as a therapeutic modality in gastric cancer may be applicable to tumours which have the capability of responding to serum associated amidated G17 and/or have autocrine/paracrine pathways involving glyG17.
The authors would like to acknowledge Mr Dan McWilliams and $\mathrm{Mr}$ Jon Hill for performing the molecular biology studies. Financial support was provided by the Aphton Corporation.

1 Kobori O, Vuillot MT, Martin F. Growth response of rat stomach cancer cells to gastro-entero-pancreatic hormones. Int $\mathcal{F}$ Cancer 1982;30:65-7.

2 Ochai A, Yasui W, Tahara E. Growth-promoting effect of gastrin on human gastric carcinoma cell line TMK-1. fpn $\mathcal{F}$ Cancer Res 1985;76:1064-71.

3 Watson S, Durrant L, Morris D. Gastrin: growth enhancing effects on human gastric and colonic tumour cells. $\mathrm{Br} \mathcal{F}$ Cancer 1989;59:554-8.

4 Moyer MP, Armstrong A, Aust JB, et al. Effects of gastrin, glutamine and somatostatin on the in vitro growth of normal and malignant human gastric mucosal cells. Arch Surg 1986;121:285-8.

5 Matsushima Y, Kinoshita Y, Nakata H, et al. Gastrin receptor gene expression in several human carcinomas. $7 p n \mathcal{F}$ Cancer Res 1994;85:819-24.

6 Ito $\mathrm{M}$, Iwata N, Taniguchi T, et al. Functional characterisation of two cholecystokinin-B/gastrin receptor isoforms: a preferential splice donor site in the human receptor gene. Cell Growth Diff 1994;5:1127-35.

7 Miyake A. A truncated isoform of human CCK-B/gastrin receptor generated by alternative usage of a novel exon. Biochem Biophys Res Commun 1995;208:230-7.

8 McWilliams DF, Watson SA, Crosbee DM, et al. Coexpression of gastrin and gastrin receptors (CCK-B and $\Delta \mathrm{CCK}-\mathrm{B}$ ) in gastrointestinal (GI) tumour cell lines. Gut 1998;4:795-8

9 Watson SA, Clarke PA, Smith AM, et al. Expression of $\mathrm{CCKB} /$ gastrin receptor isoforms in gastrointestinal tumour cells. Int 7 Cancer 1998;77:572-7.

10 Van Solinge WW, Rehfeld JF. Co-transcription of the gastrin and cholecystokinin genes with selective translation of gastrin mRNA in a human gastric carcinoma cell line. FEBS Lett 1992;309:47-50.

11 Watson SA, Durrant LG, Wncyk PM, et al. Intracellular gastrin in human gastrointestinal tumour cells. $\mathcal{F}$ Natl Cancer Inst 1991;83:866-72.

12 Wang TC, Koh TJ, Varro A, et al. Processing and proliferative effects of human progastrin in transgenic mice. 7 Clin Invest 1996;8:1918-29.

13 Seva C, Dickinson CJ, Yamada T. Growth-promoting effects of glycine-extended progastrin. Science 1994;265:410-12.

14 Stepan VM, Sawada M, Yamada T, et al. Glycine-extended gastrin exerts growth-promoting effects on colon cancer cell lines [abstract]. Gastroenterology 1996;110:A1122.

15 Baldwin GS. Binding of progastrin fragments to the $78 \mathrm{kDa}$ gastrin-binding protein. FEBS Lett 1995;359:97-100.

16 Iwase K, Evers BM, Hellmich MR, et al. Regulation of growth of human gastric cancer by gastrin and glycineextended progastrin. Gastroenterology 1997;113:782-90.

17 Watson SA, Michaeli D, Grimes S, et al. Gastrimmune raises antibodies that neutralise amidated and glycine-extended gastrin-17 and inhibit the growth of colon cancer. Cancer Res 1996;56:880-5.

18 Watson SA, Durrant LG, Morris DL. The effect of the $\mathrm{E}_{2}$ prostaglandin enprostil, and the somastatin analogue SMS 201995 , on the growth of a human gastric cell line, MKN45G. Int f Cancer 1990;45:90-4.

19 McLaughlan J, Seth R, Vautier G, et al. Interleukin-8 and inducible nitric oxide synthase mRNA levels in inflammatory bowel disease at first presentation. F Pathol 1997;181: $87-92$.

20 Nemeth J, Varro A, Bridson J, et al. Increased tissue concentrations of the gastrin precursor in patients treated with omeprazole. Eur f Cancer 1992;22:638-44.

21 Watson SA, Clifford TL, Steele RJC. Inhibitory effect of the gastrin receptor antagonist, CR2093 on the basal, gastrin stimulated and growth factor stimulated growth of the pancreatic cell line, AR42J. Anticancer Drugs 1994;5:591-4.

22 Watson SA, Michaeli D, Grimes S, et al. Anti-gastrin antibodies raised by Gastrimmune inhibit growth of the human colorectal tumour AP5. Int f Cancer 1995;61:23340 .

23 Watson SA, Michaeli D, Grimes S, et al. A comparison of an anti-gastrin antibody and cytotoxic drugs in the therapy of human gastric ascites in scid mice. Int $\mathcal{F}$ Cancer 1999;81: 248-54.

24 Watson SA, Durrant LG, Morris DL. Growth-promoting action of gastrin on human colonic and gastric tumour cells cultured in vitro. Br f Surg 1988;75:342-5.

25 Smith AM, Morris T, Michaeli D, et al. Gastrimmune induced anti-gastrin antibodies inhibit stimulated acid output in a rat gastric fistula model [abstract]. Gut 1999;44: A95.

26 Justin TA, Steele RJC, Michaeli D, et al. The effect of porcine anti-gastrin-17 antibodies on the pig gastrointestinal mucosa [abstract]. Gut 1999;4:A117. 